\title{
As ações bucais como recurso na construção de ações co-operativas
}

DOI: http://dx.doi.org/10.21165/el.v49i3.2527

\section{João Paulo da Silva ${ }^{1}$}

\section{Resumo}

Enquanto se comunicam em língua de sinais brasileira (libras), os surdos empregam diferentes formas de ação bucal. Neste trabalho, assumindo a perspectiva de teorias que buscam descrever as práticas socializadas de interagir, entender e habitar o mundo com os outros (STREECK, 2015; GOODWIN, 2018), discuto de que maneira o emprego dessas ações pode fazer parte da construção da significação em uma conversa entre dois surdos adultos proficientes em libras. Mais especificamente, procuro evidenciar como elas são usadas como material passível de ser transformado e reutilizado durante a interação na construção da significação on-line, servindo como uma parte importante de um processo co-operativo em que os agentes constroem uma nova ação a partir da decomposição e do reuso com transformações de recursos disponibilizados pela ação de outros agentes. Os dados apresentados foram transcritos no software ELAN com base no modelo de transcrição proposto por McCleary, Viotti e Leite (2010).

Palavras-chave: ações bucais; ações co-operativas; libras.

1 Universidade Federal de São Carlos (UFSCar), São Carlos, São Paulo, Brasil; jpsilva@ufscar.br; https://orcid.org/0000-0003-0474-435X 


\title{
Mouth actions as a resource in the construction of co-operative actions
}

\begin{abstract}
The deaf use different forms of mouth action when communicating in Brazilian Sign Language (Libras). Based on a theory that explains the socialized practices of interacting, understanding and inhabiting the world with others (STREECK, 2015; GOODWIN, 2018), I discuss how the use of those actions can contribute with meaning construction in a conversation between two deaf adults who are proficient in Libras. More specifically, I show how mouth actions can be used as liable material that is transformed and reused in the construction of online meaning during an interaction, serving as an important part of the co-operation process in which agents build a new action based on decomposition and reuse with transformations of resources made available by the action of other agents. The data presented were transcribed in the ELAN software based on the transcription model proposed by McCleary, Viotti and Leite (2010).
\end{abstract}

Keywords: mouth actions; co-operative actions; Libras.

\section{Introdução}

Enquanto sinalizam, os surdos empregam não só ações manuais, mas também ações realizadas por outras partes do corpo, dentre as quais, estão as ações bucais. O papel das ações bucais em interações sinalizadas ainda é pouco conhecido. A literatura que trata do fenômeno reconhece duas subcategorias: as figuras bucais (mouth pictures, mouthings) e os gestos bucais (mouth gestures). As figuras bucais têm sido descritas como aquelas ações que têm alguma associação com palavras da língua oral majoritária na região em que a língua de sinais é usada (como uma ação bucal em que os lábios se apertam e, em seguida, se abrem em formato arredondado simultaneamente ao início do sinal manual BOLA, que se assemelha à articulação da primeira sílaba da palavra "bola" em português). O fenômeno é reconhecido pela literatura como um caso de contato linguístico entre as línguas faladas e sinalizadas usadas em uma mesma região, que tem como resultado a incorporação de alguns aspectos das línguas faladas às sinalizadas. Os gestos bucais, por sua vez, são descritos como ações bucais que não têm relação com palavras de alguma língua oral, mas que, coordenadas com as ações manuais, contribuem para a construção da significação.

Em grande parte dos estudos realizados a respeito das línguas sinalizadas, a tendência é tratar essas ações como "sinais não manuais", ou ainda, "expressões não manuais", que, operando com os "sinais manuais", seriam necessários para a organização gramatical dessas línguas. Nesse sentido, uma parte da literatura que trata da questão busca evidências para o argumento de que as expressões bucais são parte do sistema 
das línguas de sinais. Em geral, essas análises levam em consideração uma possível obrigatoriedade da co-ocorrência de expressões bucais com os sinais manuais e o grau de convencionalidade das expressões bucais nas línguas sinalizadas. Outros autores buscam responder questões relacionadas à natureza dessas ações (se é linguística ou gestual) e em que medida elas são obrigatórias ou não (BANK, 2014; JOHNSTON, SCHEMBRI; ROEKEL, 2015)². Nesta perspectiva, estes autores, apoiando suas análises em um corpus robusto de dados, têm apontado para o fato de que as ações bucais, em grande parte dos casos, não são obrigatórias e somente algumas poucas delas parecem ter algum grau de convencionalidade. Não obstante, esses mesmos estudos apontam para a onipresença dessas ações nos discursos sinalizados, o que pede que o fenômeno seja mais bem detalhado.

Neste trabalho, procuro lançar um olhar diferente para o que acontece nas interações em língua sinalizada, tomando como base estudos que vêm sendo realizados a respeito de interações em línguas orais em áreas como a antropologia linguística, a etnometodologia e estudos a respeito da multimodalidade e da intercorporealidade que caracterizam as interações presenciais (CLARK, 1996; HUTCHINS, 2010; ENFIELD, 2009; KOCKELMAN, 2013; MCCLEARY; VIOTTI, 2014, 2017). Ao fazer isso, penso que essa mudança de perspectiva pode contribuir para que alguns aspectos de fenômenos como os que aqui discuto possam ser entendidos e explicitados. A perspectiva aqui assumida é a de observar as interações a partir da intercorporeidade e da multimodalidade que envolve as situações de interação presenciais, procurando entender de que maneira as pessoas se engajam com outras pessoas e com o mundo à sua volta na realização de ações conjuntas e co-operativas, desempenhando ações que façam sentido para todos os fins práticos na interação (GOODWIN, 2018; GARFINKEL, 2018 [1967]). Dessa perspectiva, é de central interesse para o trabalho descritivo a explicitação do processo de construção on-line da significação, ou seja, do modo como os participantes da interação empregam os mais diversos recursos semióticos para construir significação e interagir com o mundo material, social e cultural à sua volta, a fim de alcançar, ao menos parcialmente, os objetivos individuais e coletivos no projeto conjunto posto na interação (MCCLEARY; VIOTTI, 2017). Dessa maneira, a busca por uma delimitação categórica entre o que é linguístico e o que é gestual não se coloca como uma questão relevante para esse tipo de investigação. Em vez disso, a questão central é: o que está envolvido na compreensão mútua quando as pessoas se envolvem em atividades conjuntas e co-operativas?

Como ponto de partida para esta discussão, cabe dizer que, da perspectiva aqui assumida, que leva em consideração a dinâmica de corpos humanos vivos e a sua condição de estar no mundo, a resposta não pode ser a de que os falantes/sinalizadores se entendem simplesmente porque compartilham um sistema linguístico convencional. Essa posição - a de considerar que os significados são internos aos signos e estes, ao

2 Para discussões sobre a relação entre língua e gesto nas línguas sinalizadas, feitas a partir de diferentes perspectivas, ver McCleary e Viotti $(2010,2011,2014,2017)$ e Wilcox e Xavier (2013). 
sistema -, não pode ir muito longe na explicação de como as pessoas fazem sentido dos mais diversos projetos conjuntos em que se engajam nas interações cotidianas ${ }^{3}$. Para as questões específicas desta discussão, cabe dizer que, sem a intenção de colocar em xeque o estatuto linguístico das línguas de sinais, este trabalho busca começar a revelar, a partir dos estudos da intercorporealidade inerente à comunicação humana, características dessas línguas, que, olhando da perspectiva das práticas socializadas de interagir, entender e habitar o mundo com os outros (STREECK, 2015) possam não ter sido até agora explicitadas. Com essa mudança de perspectiva, pretendo iniciar uma exploração, nesta pesquisa ainda em andamento, do mecanismo por meio do qual as ações bucais são elaboradas nas interações, para fins locais de compreensão mútua e a favor da atividade conjunta em curso na interação.

O objetivo deste artigo é, portanto, o de buscar explicitar, a partir dos estudos da intercorporealidade e da multimodalidade, os mecanismos por meio dos quais as ações bucais são elaboradas na interação. Mais especificamente, seguindo a proposta de Goodwin, procuro observar como as pessoas constroem significação co-operativamente, na interação, não só se valendo do uso e do reuso de seus próprios recursos semióticos, mas também do reuso, com transformações, de recursos semióticos disponibilizados previamente por outro agente em ambiente público. Nos casos analisados neste trabalho, o reuso é elaborado também por meio de ações bucais.

Este artigo está organizado da seguinte maneira: na próxima seção, introduzo a noção de interação adotada tratando das bases teóricas para uma abordagem intercorporeal da ação humana com outros. Nessa apresentação, o interesse central se volta para as práticas públicas por meio das quais a interação se desenvolve. Dentre essas práticas, discuto o conceito de ações co-operativas, proposto por Charles Goodwin (2018) e argumento a favor do entendimento das ações bucais como material na elaboração de ações dessa natureza em línguas sinalizadas. Na sequência, apresento os aspectos metodológicos deste trabalho, em relação à coleta, transcrição e apresentação de dados. Por fim, apresento uma análise de algumas ocorrências de ações bucais usadas na elaboração de ações co-operativas e abro uma discussão sobre algumas implicações dos dados para a pesquisa. Encerro o artigo tecendo considerações finais sobre o trabalho e chamando a atenção para próximos passos a serem desenvolvidos nesta pesquisa em elaboração.

3 Como argumentam McCleary e Viotti (2017), apesar de essa visão de significado, postulada pela teoria do signo saussuriano, vir sendo questionada por diferentes correntes teóricas, a exemplo da linguística cognitiva, que propõe uma semiótica mais dinâmica, há mostras de que, mesmo nessa teoria, há o postulado de um significado "literal" como sendo básico, do qual seriam provenientes outros significados, com o metafórico, por exemplo. Isso leva os autores a concluir que nem mesmo essa teoria chega a se desprender completamente da tradição dos estudos da linguagem. 


\section{Corpos vivos em interação intercorporeada e multimodal}

Analisar a comunicação humana em toda a sua complexidade, levando em consideração todos os recursos semióticos envolvidos nas práticas públicas de construção de ação e de significado com outros, exige a adoção de uma concepção de corpo muito diferente daquela que normalmente é assumida em uma parte dos estudos de língua e linguagem humanas. Como argumenta Streeck (2015), a ideia de um corpo que serve simplesmente como instrumento para a produção/recepção de mensagens produzidas e recebidas por canais disponibilizados pelo corpo é associada à noção de um sistema linguístico "depositado" na mente humana. Essa noção coloca em segundo plano o papel do corpo na comunicação humana, enfatizando a importância de nossas "mentes", como poderosas "máquinas" de codificação/decodificação de mensagens. O autor argumenta que tal noção vem sendo rejeitada por novas concepções advindas de estudos em áreas como a biologia, as ciências cognitivas, a neurociência e sociologia, que se aliam a uma reinterpretação dos estudos de interação humana multimodal, cada vez mais voltadas para a descrição das práticas socializadas de interagir e habitar o mundo com outros (STREECK, 2015). Uma maneira diferente de conceber os corpos em comunicação é entendê-los como órgãos de ação/percepção/cognição, em seu engajamento com o ambiente físico, social e cultural em seu entorno.

Dessa perspectiva, a língua passa a ser vista como uma forma de ação conjunta, corporeada e situada, eminentemente multimodal. Nesse sentido, a noção de multimodalidade aqui assumida diz respeito à consideração de que todas as ações realizadas na interação participam da construção da significação on-line. Quando as pessoas se engajam em uma interação, elas pretendem levar a cabo, ao menos parcialmente, algum projeto conjunto. Para isso, elas precisam se ater aos mínimos detalhes dos eventos que constituem a interação, ou seja, ao momento em que as coisas acontecem ou não e às implicações a que a sequência de ações leva. Nesse sentido, os signos são vistos como resultantes da interação e não como um meio para ela (MCCLEARY; VIOTTI, 2017). Nesta noção, ancorada no modelo neopeirceano de signo, proposta por Kockelman (2013) e desenvolvida por Enfield (2013), os signos não são vistos como entidades estáticas, mas como parte de processos semióticos em contínua elaboração nas interações. Nesse sentido, o pareamento forma-significado, como proposto na noção saussuriana de signo, é apenas uma subestrutura idealizada de um processo semiótico mais abrangente (ENFIELD, 2013).

Na noção neopeirceana, o signo é um evento no mundo que, sendo percebido por um agente e sendo tomado por esse agente como representando naquela situação específica um certo objeto, instiga um interpretante, ou seja, uma reação do agente ao evento percebido. Esse interpretante faz sentido em termos de ser orientado para o mesmo objeto que o primeiro signo se coloca a representar. Na interação, a reação do agente (i.e., o interpretante), quando se torna pública e perceptível para o(s) outro(s), é tomada pelo(s) outro(s) agente(s) como sendo signo, que, por sua vez, vai instigar outro(s) 
interpretante(s), em um processo semiótico contínuo, em cadeia, que se desenvolve sequencialmente, no tempo (ENFIELD, 2013). É nesse sentido que se entende que as pessoas agem conjuntamente em co-operação na elaboração de signos (que envolve o reuso, com transformações, de formas já fixadas e em uso em uma comunidade, bem como a repetição de usos em diferentes níveis estruturais).

Como esse processo semiótico se desenvolve no tempo, a noção de sequencialidade é central, no sentido de que uma ação na interação está sempre relacionada a uma ação produzida anteriormente por outro interlocutor. A co-construção dos signos, dessa perspectiva, envolve um ajuste afinado entre os interactantes ao longo da interação. Se tomarmos como exemplo um par adjacente do tipo pergunta-resposta, fica evidente que, ao tomar a palavra, um falante demonstra que entendeu que o turno de fala de seu interlocutor acabou e ele entendeu a elocução anterior como uma pergunta (LODER; SALIMEN; MÜLLER, 2008). Assim, o entendimento é sinalizado por meio da construção competente de uma próxima ação de modo apropriado (GOODWIN, 2018). Da sequencialidade das ações da interação decorre que os participantes têm a possibilidade de construir novas ações com base em materiais dispostos por um agente anterior no ambiente da interação. A partir desse entendimento, apresento a seguir a noção de ações co-operativas, como proposta por Charles Goodwin (2018).

\section{Ações co-operativas}

Para Goodwin (2018), as ações co-operativas são elaboradas combinando materiais que têm propriedades diferentes em um pacote de ação local, construindo uma ação cujos atributos não podem ser encontrados em nenhum dos elementos isoladamente ${ }^{4}$. Embora o autor inicie a discussão apresentando um exemplo de ação co-operativa envolvendo língua, ele prontamente esclarece que ações co-operativas não se restringem a ela, mas estão na base das mais diversas formas de vida social e cognitiva dos seres humanos, tais como o uso de diversas ferramentas e artefatos materiais, a construção de novos tipos de objeto, a construção de cultura e de novos ambientes, diversas formas de aprendizagem social, dentre outros. A figura a seguir, adaptada de Goodwin, ilustra esse processo com dois exemplos distintos: um deles em que ilustra artefatos materiais que vão sendo modificados ao longo do tempo pela ação de outros agentes; e um segundo exemplo envolvendo o uso local de enunciados linguísticos por crianças durante uma brincadeira.

4 Goodwin (2018) esclarece que o conceito de "co-operação" não deve ser confundido com "cooperação", no sentido que é conceitualizado e investigado pela antropologia biológica. Diferente de cooperação, o conceito de co-operação não está relacionado à noção de ajuda mutual ou a propósitos teleológicos de benefício do outro. 
Figura 1. Construção de uma nova ação por meio de transformações cumulativas desempenhadas sobre materiais criados por ações prévias de outros atores

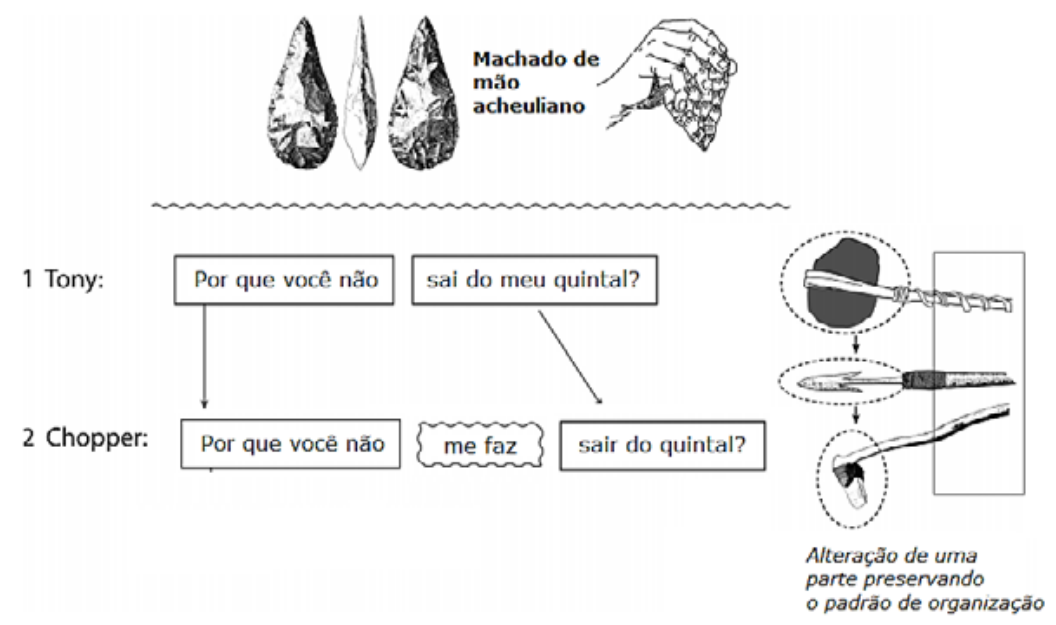

Fonte: Goodwin (2018, p. 4)

A discussão apresentada pelo autor a partir desse exemplo é a de que os enunciados linguísticos, tal como os instrumentos de pedra, são produzidos a partir de ações que, uma vez elaboradas, criam materiais públicos disponíveis para reuso por outros agentes. A figura ilustra o processo de reuso da pedra como instrumento, partindo da ação de segurar a pedra diretamente com a mão até a ação de segurá-la por meio de um outro suporte; é alcançado por meio de ações sobre esse material que promovem uma mudança de parte de sua estrutura, ao mesmo tempo em que se preserva o padrão de organização: a mão, que serve de suporte para segurar a pedra, é substituída por outros suportes, possibilitando outros usos desse material. O argumento é o de que essas ações, que Goodwin chama de co-operativas, estão na base do processo de todas as formas de socialidade humana. Nesse sentido, elas operam também no uso de enunciados linguísticos. No exemplo ilustrado pela figura, os enunciados foram produzidos em uma interação entre crianças afro-americanas que estavam brincando na rua. $\mathrm{O}$ argumento do autor é o de que a ação da primeira criança, Tony, é construída a partir da junção de diferentes partes (neste caso, cada uma das palavras que ela emprega) para criar alguma coisa que não pode ser encontrada em nenhuma das partes isoladamente. A segunda criança, Chopper, constrói uma nova ação desempenhando operações sistemáticas sobre o material encontrado na ação de Tony, a saber: i) decomposição de arranjo combinatório, por meio da separação do enunciado de diferentes peças "por que você não" e "sai do meu quintal"; iii) reuso dessas partes, incorporando-as como elemento de seu próprio enunciado; iv) rearranjando essas partes para adicionar algo novo a elas: "me faz (sair)" (GOODWIN, 2018, p. 2).

5 A modificação da forma do verbo se dá apenas na tradução do exemplo para o português neste trabalho. Em inglês (no original), a forma do verbo "get out" é mantida no segundo enunciado: "why don't you get out my yard?" e "why don't you make me get out the yard?". 
Ao tratarmos as ações bucais como recurso na construção de ações co-operativas, um esclarecimento se faz necessário: as ações co-operativas não são elaboradas apenas com elementos propriamente linguísticos. Toda ação corporal é, potencialmente, um recurso semiótico passível de ser usado na construção desse tipo de ação. O entendimento das ações bucais como material disponível para reuso e para transformações nas práticas públicas de habitar as ações dos outros pode ajudar a solver problemas ainda não resolvidos na resolução de como os sinalizadores surdos fazem uso das ações bucais e o grau de conhecimento do português envolvido no uso das figuras bucais nas interações nessas línguas. Nesse sentido, este trabalho se volta para a descrição de como essas ações são elaboradas na própria interação, com base no reuso dos materiais disponibilizados nas práticas públicas da interação local, de modo que a proposta é a de observar a dinâmica de elaboração local dessas ações para fins de construção da significação.

\section{Metodologia}

Em uma análise como a que aqui é proposta, em que se busca descrever os recursos semióticos empregados na interação em detalhes a partir da observação de interações semiespontâneas ${ }^{6}$, alguns cuidados metodológicos se fazem necessários. 0 primeiro deles diz respeito à qualidade da filmagem da interação, uma vez que descuidos nesse sentido podem dificultar a observação de detalhes da sinalização relevantes para as análises. No caso de pesquisas que olham para detalhes específicos da face dos sinalizadores, como é o caso desta, uma tomada de filmagem com captação do rosto, além daquela que capta o espaço de sinalização, é imprescindível. Os pesquisadores que compõem o Laboratório "Linguagem, Interação, Cultura e Cognição" (LLICC) já estavam atentos a isso desde o início, o que possibilitou que as primeiras filmagens do corpus já fossem registradas com cinco câmeras registrando diferentes tomadas. Os vídeos que compõem o corpus desta pesquisa são advindos do corpus do LLICC e já foram usados por Leite (2008) em pesquisa de doutorado. Trata-se de três vídeos de duração média de vinte minutos, com três sinalizadores diferentes conversando entre si em pares, em

\footnotetext{
60 tipo de interação aqui analisada é considerado semiespontâneo pela estratégia utilizada na coleta dos dados: a gravação de uma conversa entre surdos num estúdio previamente arranjado. Essa estratégia coloca ênfase sobre o caráter natural dos dados (advindo da livre conversa entre os participantes), embora envolva alguma manipulação (advinda da preparação de um ambiente específico para a realização da filmagem).

7 Tarcísio de Arantes Leite registrou a conversa aqui apresentada e transcreveu minuciosamente os três minutos iniciais. Agradeço ao Tarcísio, bem como aos coordenadores do LLICC, o Prof. Dr. Leland McCleary e a Profa. Dra. Evani Viotti (USP), por disponibilizar os dados para esta pesquisa. Agradeço também a Regiane Agrella e a Wilson Santos Silva (colaboradores surdos), pela participação na gravação e por permitirem a divulgação de seus nomes reais e de suas imagens nas pesquisas com esta conversa. Sem essa valiosa colaboração, essas pesquisas não seriam possíveis.
} 
cada uma das conversas. Os excertos que apresento neste artigo são provenientes da conversa entre Regiane Agrella e Wilson Santos Silva. A imagem a seguir mostra os vídeos da conversa a que me refiro já inseridos no programa ELAN, usado para transcrição dos dados da pesquisa. As vantagens do uso do ELAN são a possibilidade de i) sincronização dos vídeos (até quatro vídeos ao mesmo tempo) com as anotações; ii) enquadramento do rosto, que permite a visualização de detalhes da ação facial, de um ângulo privilegiado; e iii) facilidade na busca dos dados anotados.

Figura 2. Imagem da tela do Elan, exibindo a disponibilização de quatro vídeos

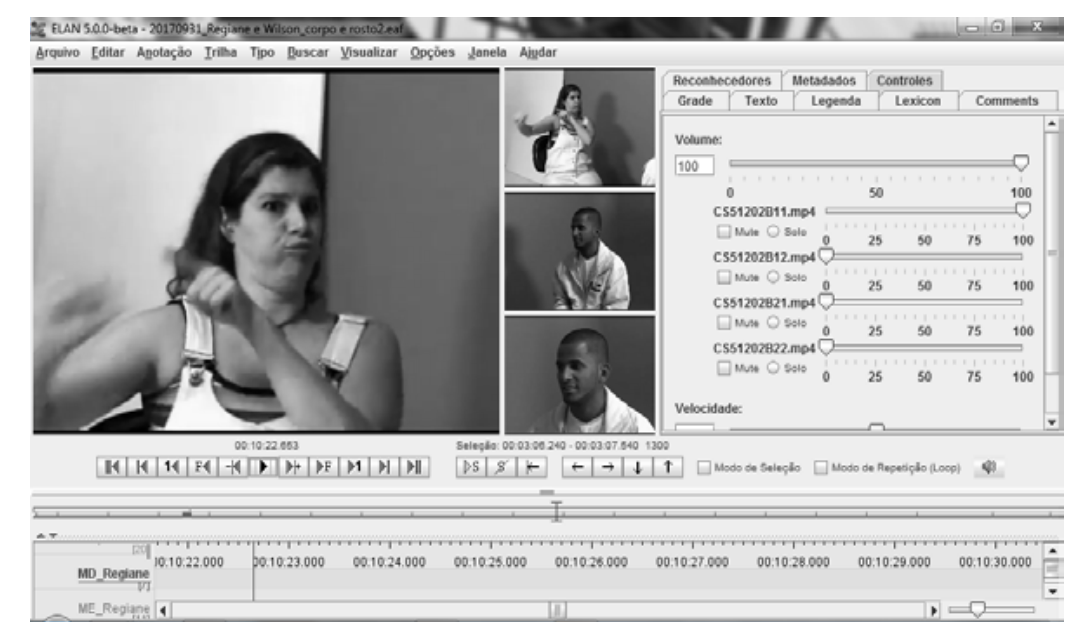

Fonte: Elaboração própria

Em relação ao modelo de transcrição para anotar os dados, utilizei aquele proposto por McCleary, Viotti e Leite (2010) para anotação de dados sinalizados. Dentre as vantagens desse modelo de transcrição estão o fato de que: i) é um modelo de transcrição eminentemente descritivo, que busca, tanto quanto possível, não imprimir sobre os dados uma determinada categoria de análise previamente; ii) permite a anotação em trilhas diferentes para diferentes articuladores, possibilitando observar separada e sincronicamente o que acontece em cada parte do corpo; iii) sistematiza detalhes importantes que normalmente são observados nas pesquisas em estudos dos gestos, como identificação de unidades gestuais, e de fases do gesto (KITA et al., 1998), que são trilhas que vão me ajudar a observar a sincronia entre mão e boca; e iv) traz um vocabulário controlado já previamente definido para gestos bucais, que está facilitando as anotações iniciais. Novos acréscimos estão sendo incluídos a esse vocabulário controlado quando necessário.

Ainda em relação à transcrição, enfatizo a importância de transcrever por completo os dados dos discursos sinalizados, e não apenas a anotação das sinais manuais, como se observa em muitos trabalhos. No caso deste trabalho, se se quer entender a ação co- 
operativa, é preciso fazer uma descrição minuciosa das ações corporais, visto que toda ação pode ser um recurso semiótico. Por questão de tempo, contudo, estou iniciando as transcrições, nessa conversa, pelas seguintes trilhas: unidade entoacional (iu), unidade gestual, fases do gesto, tipo de gesto e descrição do gesto (todas elas olhando separadamente para a mão direita e para a mão esquerda) e, naturalmente, as trilhas concernentes às figuras bucais e aos gestos bucais. Para transcrever as figuras bucais, vali-me da catalogação de visemas do português brasileiro, feita por DeMartino (2005); para transcrever os gestos bucais, baseei-me, a princípio, no vocabulário controlado já existente no modelo de McCleary, Viotti e Leite (2010).

Um dos desafios que se coloca para este trabalho no momento, em termos metodológicos, é o de capturar na transcrição de figuras bucais as sutilezas da produção dessas formas. Ao utilizar o modelo de DeMartino, desenvolvido para a anotação de visemas do português brasileiro, há o benefício de que as configurações de boca que se assemelham à articulação de consoantes e vogais do português possam ser anotadas por meio de símbolos de fácil reconhecimento. Nessas anotações, consideram-se os aspectos visíveis da articulação, de modo que um símbolo como [p] é usado para anotar uma ação em que os lábios iniciam pressionados com tensão, e em seguida, são abertos com um pequeno sopro. Há, contudo, casos em que os visemas são de difícil visualização, outros que, prototipicamente, seriam produzidos de um modo diferente por falantes do português ao articular aquele visema específico. Assim, neste estágio da pesquisa, estou buscando maneiras de descrever precisamente essas formas criadas na interação.

Em relação à apresentação dos dados neste artigo, vou ilustrar a transcrição por meio de imagens retiradas da própria transcrição no ELAN, seguidas de sua descrição, textualmente. Para facilitar a visualização, as imagens da transcrição no ELAN são acompanhadas da transcrição da glosa dos sinais e das figuras bucais num quadro abaixo da imagem da transcrição no ELAN.

\section{Análises}

Nesta seção, apresento a análise de três ocorrências selecionadas do corpus. Com essas análises, argumento a favor do aspecto dinâmico do emprego das ações bucais, elaboradas na interação por meio de ação co-operativa. Como pretendo demonstrar a seguir, os sinalizadores, engajados na tarefa de construir ação e significado, estão atentos aos mínimos detalhes dos recursos usados pelo outro para construir significação e, durante a interação, reusam materiais criados pelo outro, com transformações, para construir suas próprias ações. A imagem a seguir ilustra o primeiro excerto da interação em análise: 
Figura 3. Excerto 1: EXPLICAR [ep]

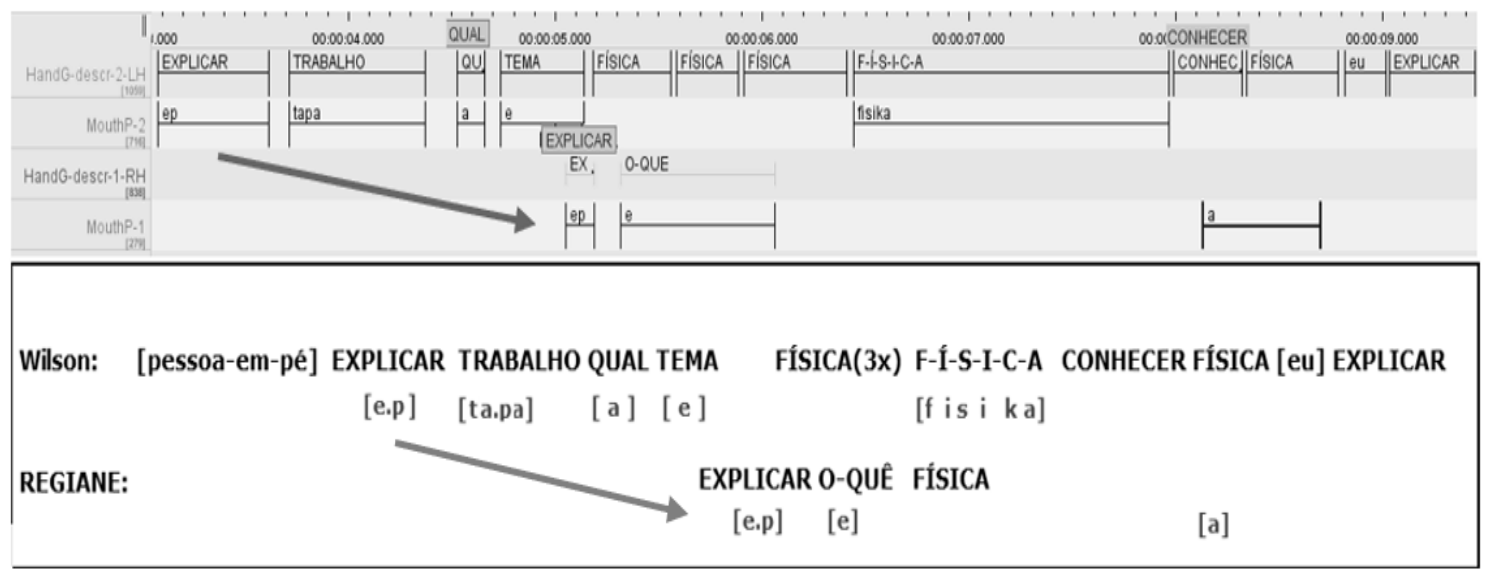

Fonte: Elaboração própria

Nesse excerto, observa-se que Regiane constrói seu enunciado aproveitando, com transformações, o material criado por Wilson previamente. Para isso, ela mantém a estrutura criada a partir de EXPLICAR TRABALHAR QUAL TEMA e, decompondo esse enunciado em partes menores, mantém EXPLICAR e a figura bucal [e.p] e, deletando os demais sinais manuais e ações bucais, aloca o sinal O-QUE acompanhado da figura bucal [e]. Regiane não conhecia o sinal usado por Wilson para significar "física". Ele enuncia o sinal três vezes, mas, como ela continua mostrando que não entendeu, ele soletra manualmente a palavra, acompanhando a soletração de uma articulação bucal da palavra "física". Em seguida, Regiane reage, demonstrando entendimento (ah!). Nas ocorrências de ação bucal observadas nesse excerto, as figuras bucais são criadas em sincronia com os sinais manuais, sendo que, com exceção da figura bucal [fisika] ${ }^{8}$, todas as demais figuras bucais são elaboradas a partir de uma parte da palavra equivalente em português. Observemos um exemplo semelhante no excerto 2, a seguir.

Figura 4. Excerto 2: A-T-O-M-I-C-A [atomika] BOMBA [pu]

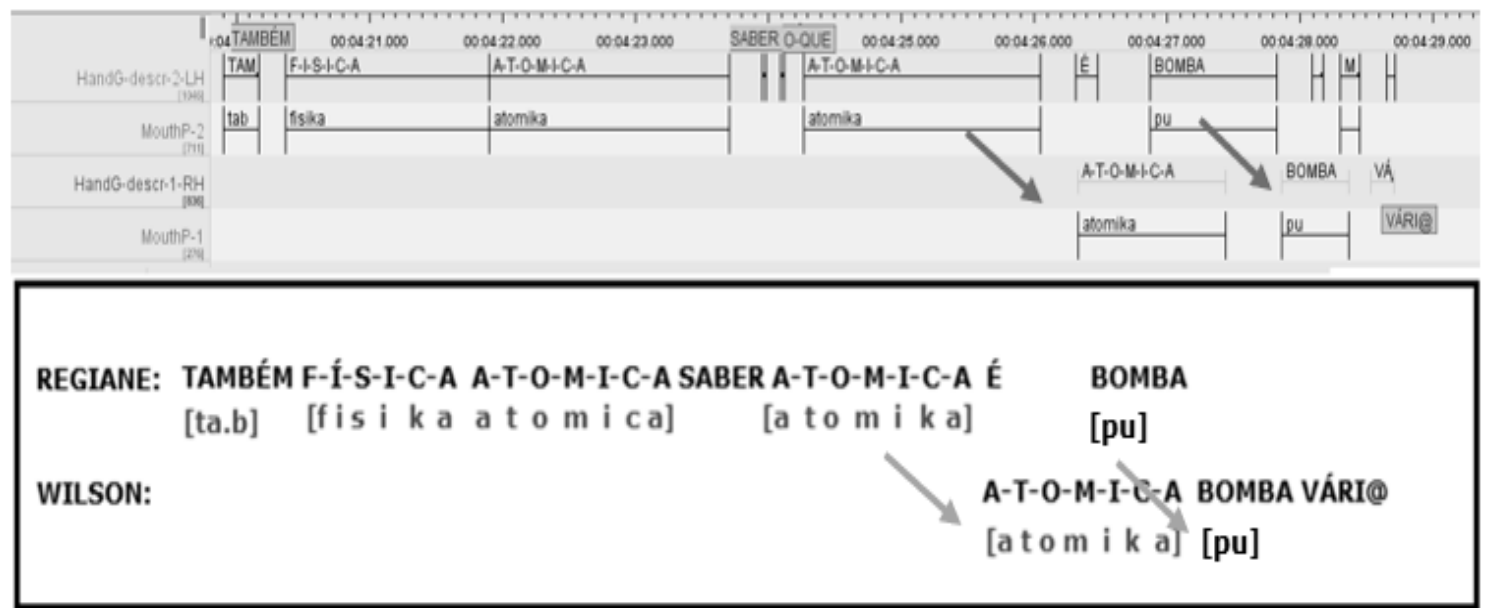

Fonte: Elaboração própria

8 Por causa da abertura da boca na produção da vogal final na ação da sinalizadora, não estou fazendo distinção entre a forma tônica e átona nesta anotação. 
Nesse excerto observa-se que Regiane menciona "física atômica" e, em seguida, pergunta se o seu interlocutor sabe o que significa "atômica", respondendo, ela mesma, que é relacionada a "bombas". Para dizer isso, ela realiza a soletração manual da expressão "física atômica" e, depois de realizar o sinal SABER, soletra novamente "atômica", sinalizando, em seguida, É BOMBA. Quando ela inicia a realização do sinal É, Wilson começa a soletrar manualmente a palavra "atômica", seguida do sinal BOMBA VÁRI@, como confirmação de que ele conhecia a expressão e concordava com o significado atribuído por Regiane para ela. A imagem a seguir do excerto mostra que Regiane usou as figuras bucais sincronizadamente com a soletração manual F-Í-S-Í-C-A A-T-O-M-I-C-A, depois durante a segunda ocorrência de A-T-O-M-I-C-A e uma ação bucal simultânea à realização de BOMBA que anotei como [pu]. Na sua confirmação, tal como realizado por Regiane, Wilson emprega uma sequência de figura bucal semelhante à realizada anteriormente por Regiane durante a realização de A-T-Ô-M-I-C-A e reusa a mesma ação bucal simultânea à realização de BOMBA. Nesse trecho, Wilson confirma o entendimento do termo "atômica", em português, empregando recursos já disponibilizados por Regiane previamente (soletração de A-T-O-M-I-C-A acompanhada da sequência bem articulada de visemas) e o sinal BOMBA, acompanhado da ação bucal [pu].

No terceiro excerto, que na interação acontece antes do excerto 2, temos uma ocorrência diferente de ação bucal, como se observa na figura a seguir.

Figura 5. Excerto 3: SABER [sabe]; $\varnothing$ [sabe]

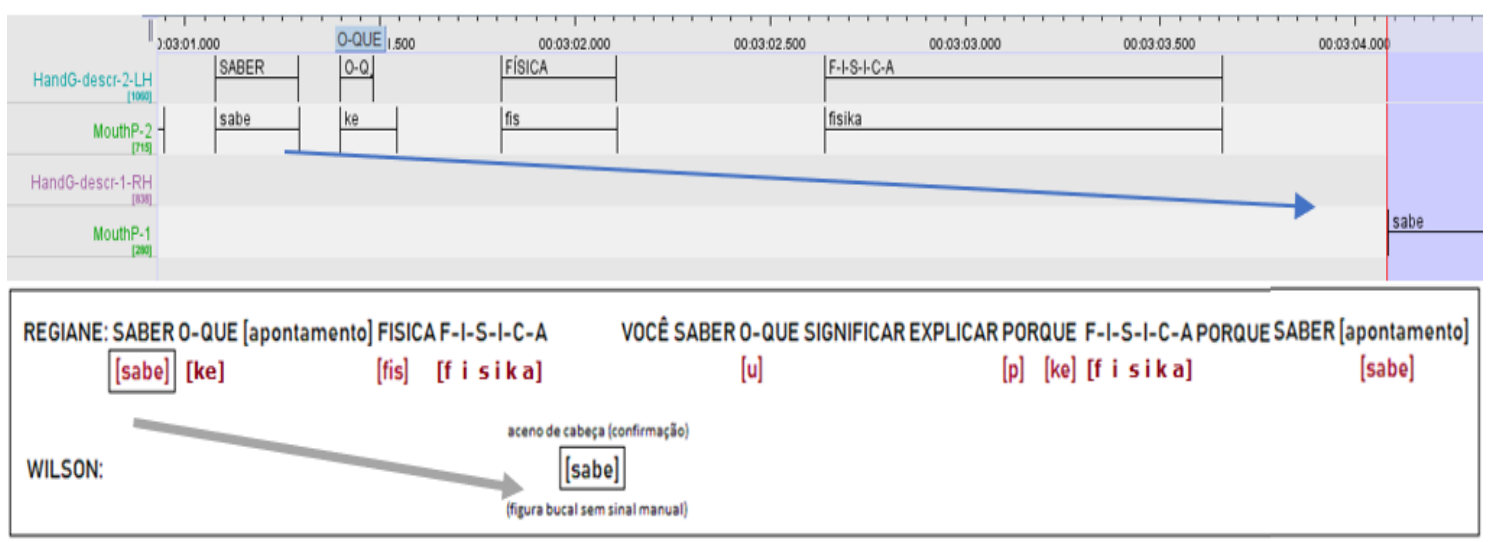

Fonte: Elaboração própria

Nessa ocorrência, observa-se que Regiane emprega algumas figuras bucais, dentre elas, a figura [sabe] enquanto sinaliza manualmente SABER9. Ao final dessa pergunta, enquanto faz uma pausa para iniciar a segunda pergunta, Wilson acena positivamente

9 Por causa da abertura da boca na produção da vogal final na ação da sinalizadora, estou considerando a produção de [e] final, e não [i], na realização desta figura bucal. 
com a cabeça e, sem realizar nenhum sinal manual, articula a figura bucal [sabe]. Tal como nas ocorrências anteriores, a figura bucal é reaproveitada do enunciado disponibilizado anteriormente em público na interação.

\section{Discussão}

A descrição das ações bucais feitas pelos surdos durante as sinalizações é uma parte importante da descrição das línguas sinalizadas ainda pouco desenvolvida. Os estudos já realizados a respeito do tema têm, em sua maioria, dado um tratamento descorporeado ao fenômeno, voltando o foco de sua atenção à descrição dessas formas como abstraídas das práticas corporeadas em que elas estão inseridas na tarefa de agir conjuntamente com outros, criando significados na interação. Nesse tratamento dado pela literatura, a tendência é considerar as figuras bucais como sendo caso de contato entre línguas. No caso dos gestos bucais, eles tendem a ser vistos como formas que, possivelmente, podem ter emergido de gestos produzidos pela comunidade ouvinte que, de alguma maneira, foram incorporadas ao sistema das línguas de sinais. Uma vez incorporados, importa, nessa literatura, para a descrição a forma empregada e não as práticas por meio das quais essas formas são elaboradas na interação. Em ambos os casos, coloca-se em primeiro plano a descrição das formas. Neste trabalho, a tentativa é a de começar a pensar uma possibilidade de tratamento diferente para o fenômeno, inserindo-o no conjunto das práticas corporeadas que realizamos com outros, que são constituídas por meio de ações públicas produzidas por agentes, que, inseridos em uma dada comunidade, desempenham essas práticas co-operativamente. Como discutido anteriormente, a ideia aqui é a de que, nas interações, as pessoas constroem ações incorporando cumulativamente recursos fornecidos previamente por outro agente: esse é um dos modos pelos quais nós habitamos as ações dos outros (GOODWIN, 2018).

Os dados analisados evidenciam que as ações bucais podem ser usadas na construção de ações co-operativas em interações em libras. Nos exemplos apresentados, as ações bucais parecem estar sendo usadas, fundamentalmente, como parte de uma ação cooperativa que visa a esclarecer o significado de um sinal e para construir uma resposta adequada à ação anterior de outro agente. Essas ações, como apresentado, podem envolver o uso simultâneo e sincronizado de ações manuais e bucais, bem como apenas ações manuais ou ações bucais. Nesta análise, foi de central interesse observar como as ações bucais são reusadas como material disponibilizado pela ação de um agente anterior na interação. A proposta aqui é a de que esse tratamento dos dados pode fornecer evidências empíricas para a descrição de como as ações bucais são efetivamente empregadas nas interações.

Nessa discussão, leva-se em consideração o fato de que as comunidades de sinalizadores são compostas não só de pessoas surdas que usam uma língua de sinais e se identificam culturalmente como membros de uma comunidade surda, mas também de outros indivíduos que usam essa mesma língua de sinais e, dada a sua inserção nas práticas 
dessa comunidade, são aceitos como parte dela, apesar de não serem fisicamente surdos (STROBEL, 2008) ${ }^{10}$. Esse cenário já configura, por si só, um ambiente em que há um intenso compartilhamento de recursos semióticos de natureza diversa comuns a todos esses indivíduos nas interações em línguas sinalizadas ${ }^{11}$. Desse modo, entende-se que as ações bucais são parte natural das interações entre surdos e surdos e entre surdos e ouvintes, que empregam essas formas com diferentes níveis de conhecimento a respeito das línguas envolvidas. De qualquer modo, a descrição neste trabalho se volta para a maneira como os sinalizadores empregam essas ações, como recursos semióticos que são, de modo a iniciar uma discussão sobre como essas ações contribuem com a significação nas interações de que participam. O caminho percorrido por esta pesquisa em elaboração é o de descrever, por meio da observação minuciosa das ocorrências de ações bucais, o papel que essas ações estão desempenhando na interação, no momento preciso em que elas são empregadas em uma interação específica. O uso dessas ações, do modo cumulativo com transformações que são centrais para as ações co-operativas, acaba por criar materiais que apresentam uma grande variedade de formas nas interações. Nesse sentido, é parte dos próximos passos da pesquisa buscar descrever, a partir da análise das ações bucais, uma parte dessa diversidade de recursos semióticos elaborados nessas interações, com o detalhamento empírico necessário à descrição e ao entendimento de como essas ações são efetivamente empregadas nas interações em libras.

\section{Considerações finais}

Este artigo teve como objetivo discutir o emprego de ações bucais nas interações em libras a partir do conceito de ação co-operativa de Goodwin (2018). Nessa discussão, chamei a atenção para o fato de que essas ações podem participar da construção de ações co-operativas, isto é, uma vez que tenham sido criadas por um agente na interação,

10 Karin Strobel, pesquisadora surda, assume uma posição política a esse respeito, afirmando que a própria categoria comunidade surda inclui tanto pessoas surdas quanto ouvintes. Nas palavras dela, "a comunidade surda de fato não é só de sujeitos surdos, há também sujeitos ouvintes membros de família, intérpretes, professores, amigos e outros - que participam e compartilham os mesmos interesses em comum em uma determinada localização" (STROBEL, 2008, p. 29). Neste trabalho, embora reconhecendo a abrangência do conceito em seu sentido político, emprego o termo comunidade de sinalizadores para abarcar tanto ouvintes quanto surdos, na tentativa de evitar a ambiguidade que o termo comunidade surda possa apresentar para os fins desta pesquisa.

11 Essa observação não encerra, contudo, todas as formas possíveis de contato que pessoas surdas podem ter com o português. Além do contato com pessoas ouvintes sinalizadoras e não sinalizadoras, há muitos caminhos de contato: além da interação com o português escrito, os surdos podem ter contato com ações bucais advindas do português não mais por contato direto com ouvintes, falantes do português, mas por contato com outros surdos, que têm contato com ouvintes falantes do português. Assim, o emprego da figura bucal por um sinalizador surdo, num determinado momento de fala, ecoa todas as interações que o sinalizador teve até aquele momento e tem a ver com qual é a melhor maneira de se comunicar com aquela pessoa específica, naquela interação. Agradeço ao Prof. Dr. Leland McCleary por essa observação (comunicação pessoal). 
elas se tornam materiais passíveis de serem reusados com transformações por outro agente. Esse olhar para as ações bucais coloca em primeiro plano o caráter corporeado dessas ações, elaboradas em benefício da construção de significação on-line e do projeto conjunto em curso na interação. Além disso, a partir da análise dessas ações, é possível perceber que todos os movimentos do corpo podem ser um signo na interação em línguas sinalizadas. Nesse sentido, é preciso explorar como cada movimento do corpo colabora para a construção do significado em interação; não apenas olhando para como os sinalizadores empregam os seus recursos semióticos na construção de significação, mas, fundamentalmente, como eles reusam com transformações materiais disponibilizados pelos recursos das ações de outros agentes, já disponibilizados em ambiente público. Finalmente, discuti algumas das consequências desse tratamento para a anotação e futuras análises dos dados e apontei os próximos passos desta pesquisa em andamento.

\section{Agradecimentos}

Agradeço ao Programa de Pós-graduação em Linguística da Universidade de São Paulo pela oportunidade que estou tendo de desenvolver, em seu âmbito, a pesquisa de doutoramento de que este trabalho faz parte.

\section{REFERÊNCIAS}

BANK, R. The ubiquity of mouthings in NGT: a corpus study. 2014. Tese (Doutorado em Linguística) - Radboud Universiteit Nijmegen, Amsterdam, 2014.

CLARK, H. Using Language. Cambridge: Cambridge University Press, 1996.

DEMARTINO, J. M. Animação facial sincronizada com a fala: visemas dependentes do contexto fonético para o português do Brasil. 2005. Tese (Doutorado em Engenharia Elétrica) - Faculdade de Engenharia Elétrica e de Computação, Universidade Estadual de Campinas, Campinas 2005.

ENFIELD, N. J. The anatomy of meaning: speech, gesture and composite utterances. Cambridge: Cambridge University Press, 2009.

ENFIELD, N. J. Relationship thinking: agency, enchrony and human sociality. Cambridge: Cambridge University Press, 2013.

GARFINKEL, H. Estudos de Etnometodologia. São Paulo: Editora Vozes, 2018.

GOODWIN, C. Co-operative action. Cambridge: Cambridge University Press, 2018. 
HUTCHINS, E. Imagining the cognitive life of things. In: MALAFOURIS, L.; RENFREW, C. The cognitive life of things: recasting the boundaries of the mind. Cambridge, UK: McDonald Institute Monographs, 2010. p. 91-102.

JOHNSTON, T.; SCHEMBRI, A.; ROEKEL, J. On the conventionalization of mouth actions in Australian Sign Language. Language and Speech, p. 1-40, fev. 2015.

KITA, S.; VAN GIJN, I.; HULST, H. Movement Phases in Sign and CoSpeech Gestures and their transcription by Human Coders. In: Proceedings of the Internacional Workshop. Ed. Ipke Wachsmuth and Martin Fröhlich, p. 23-35. Bielefeld, Germany, 1997.

KOCKELMAN, P. Agent, Person, Subject, Self: a theory of ontology, interaction and infrastructure. New York: Oxford University Press, 2013.

LEITE, T. de A. A segmentação da língua de sinais brasileira (libras): um estudo linguístico descritivo a partir da conversação espontânea entre surdos. 2008. Tese (Doutorado em Estudos Linguísticos e Literários em Inglês) - Faculdade de Filosofia, Letras e Ciências Humanas, Universidade de São Paulo, São Paulo, 2008.

LODER, L. L.; SALIMEN, P. G.; MÜLLER, M. Noções fundamentais: sequencialidade, adjacência e preferência. In: LODER, L. L.; JUNG, N. M. Fala-em-interação social: introdução à Análise da Conversa Etnometodológica. Campinas: Mercado das Letras, 2008. p. 39-58.

MCCLEARY, L.; VIOTTI, E. Sign-gesture symbiosis in Brazilian Sign Language narrative. In: PERRILL, F.; TOBIN, V.; TURNER, M. (org.). Meaning, Form and Body. Stanford: CSLI, 2010. p. 181-201.

MCCLEARY, L.; VIOTTI, E. Língua e gesto em línguas sinalizadas. Veredas (UFJF Online), v. 1, p. 289-304, 2011. Disponível em: http://www.ufjf.br/revistaveredas/files/2011/05/ ARTIGO-212.pdf. Acesso em: 15 set. 2019.

MCCLEARY, L.; VIOTTI, E. Espaços integrados e corpos partidos: vozes e perspectivas narrativas em línguas sinalizadas. Scripta, v. 18, n. 34, 2014. Disponível em: periodicos. pucminas.br/index.php/scripta/article/view/P.2358-3428.2014v18n34p121. Acesso em: 31 ago. 2019.

MCCLEARY, L.; VIOTTI, E. Fundamentos para uma semiótica de corpos em ação. In: FIORIN, J. L. (org.). Novos caminhos da Linguística. São Paulo: Editora Contexto, 2017. p. 171-193. 
MCCLEARY, L.; VIOTTI, E.; LEITE, T. de A. Descrição das línguas sinalizadas: a questão da transcrição dos dados. Alfa, v. 54, n. 1, p. 256-289, 2010. Disponível em: periodicos.fclar. unesp.br/index.php/alfa/article/viewFile/2880/2654. Acesso em: 31 ago. 2019.

STREECK, J. Embodiment in Human Communication. Annual Review of Anthropology, v. 44, p. 419-438, 2015.

STROBEL, K. As imagens do outro sobre a cultura surda. Florianópolis: Editora da UFSC, 2008 .

WILCOX, S.; XAVIER, A. N. Um quadro teórico para um tratamento unificado das línguas faladas, línguas sinalizadas e gestos. Todas as Letras, São Paulo, v. 15, n. 1, p. 88-110, 2013. 